\title{
A EDIFICIAÇÃO DO POSTULADO GEOMORFOLÓGICO E SUA CONTRIBUIÇÃO AO PLANEJAMENTO AMBIENTAL
}

\author{
Lucas Prado Osco, Rodrigo Coladello Oliveira, Marcos Norberto Boin \\ Universidade do Oeste Paulista - UNOESTE. Mestrado em Meio Ambiente e Desenvolvimento Regional, Presidente \\ Prudente-SP. E-mail: pradoosco@gmail.com
}

\begin{abstract}
RESUMO
O presente artigo tem por objetivo principal resgatar a origem do pensamento geomorfológico, de modo a abordar obras que culminaram para o advento da ciência. Para tanto, abordam-se em especial os autores responsáveis por contribuir com a consolidação do conhecimento geomorfológico. A síntese dessas informações, organizadas durante o decorrer do texto, evidenciam a colaboração de diversas obras na análise funcional dos elementos da paisagem. A metodologia adotada embasou-se na análise e levantamento de autores e obras bibliográficas que ressaltassem os estudos geomorfológicos ao longo dos séculos passados. Para tanto, os elementos levantados no estudo contribuíram para o advento da avaliação e diagnóstico do meio físico, pressuposto necessário para medidas como o planejamento ambiental. $\mathrm{O}$ artigo, portanto, enfocase nesse aspecto, com o intuito de relacionar o estudo geomorfológico aos instrumentos necessários para a análise integrada da paisagem.

Palavras-chave: Geomorfologia. Escola Alemã. Escola Anglo-Americana. Paisagem.

\section{THE EDIFICATION OF THE GEOMORPHOLOGICAL POSTULATE AND ITS CONTRIBUTION TO THE ENVIRONMENTAL PLANNING.}

\begin{abstract}
This article's main objective is to rescue the geomorphological origin of thought, in order to address works that led to the advent of the science. For that, we discuss in particular the authors responsible for contributing to consolidation of the geomorphological knowledge. The synthesis of this information, organized during the course of the text, highlight the collaboration of several works on the functional analysis of landscape elements. The adopted methodology focused on an analysis and survey of authors and bibliographical works about the geomorphological science over the past centuries. Therefore, the elements raised in the study contributed to the advent of the evaluation and diagnosis of the physical environment, necessary presupposition for measures such as environmental planning. The article focuses on that aspect, in order to relate the geomorphological study as an instrument necessary for integrated landscape analysis.
\end{abstract}

Keywords: Geomorphology. German School. Anglo-American School. Landscape. 
INTRODUÇÃO

Hugget (2007) argumenta que a origem do pensamento geomorfológico remonta à Grécia e Roma antigas, quando filósofos e estudiosos buscavam compreender a gênese de montanhas e das demais formas do relevo. Dessa maneira, pensadores discutiam o comportamento das águas e sua correlação com a paisagem, relacionando-a como um agente essencial na modificação da superfície. Chorley et al. (1964) demonstram que ao decorrer dos séculos posteriores, o pensamento geomorfológico passou a incorporar outros fatores de influência, não se restringindo apenas à força e movimentação das águas. Ressalta-se que, por conta do domínio religioso postergado até o século XIV, muitas informações de cunho científico principalmente de compreensão à dinâmica ambiental - se perderam. Somente durante o decorrer do período renascentista que os estudiosos novamente conseguiram debater a história da Terra.
Não obstante, o nascimento da geomorfologia decorreu-se no fim do século XVIII, com o químico, médico e estudioso da gênese do solo e da geologia, James Hutton (1726-1797). Ao trabalhar com os processos fluviais e defender a capacidade modeladora dos cursos d'água, Hutton forneceu bases para a fundamentação geomorfológica moderna. Posteriormente, no século XIX, os estudos geológicos da crosta terrestre de tendência naturalista contribuíram para obras de destaque geomorfológico. $O$ estudo, portanto, prossegue para se tornar uma ciência de caráter próprio, afastando-se da geografia e geologia. Abreu (1982), ao abordar a gênese do pensamento geomorfológico, destaca duas linhas epistemológicas definidas sobre os estudos referentes ao modelado terrestre, consolidadas durante o final do século XIX, classificando-as como linhagens angloamericana e germânica (Figura 1). 


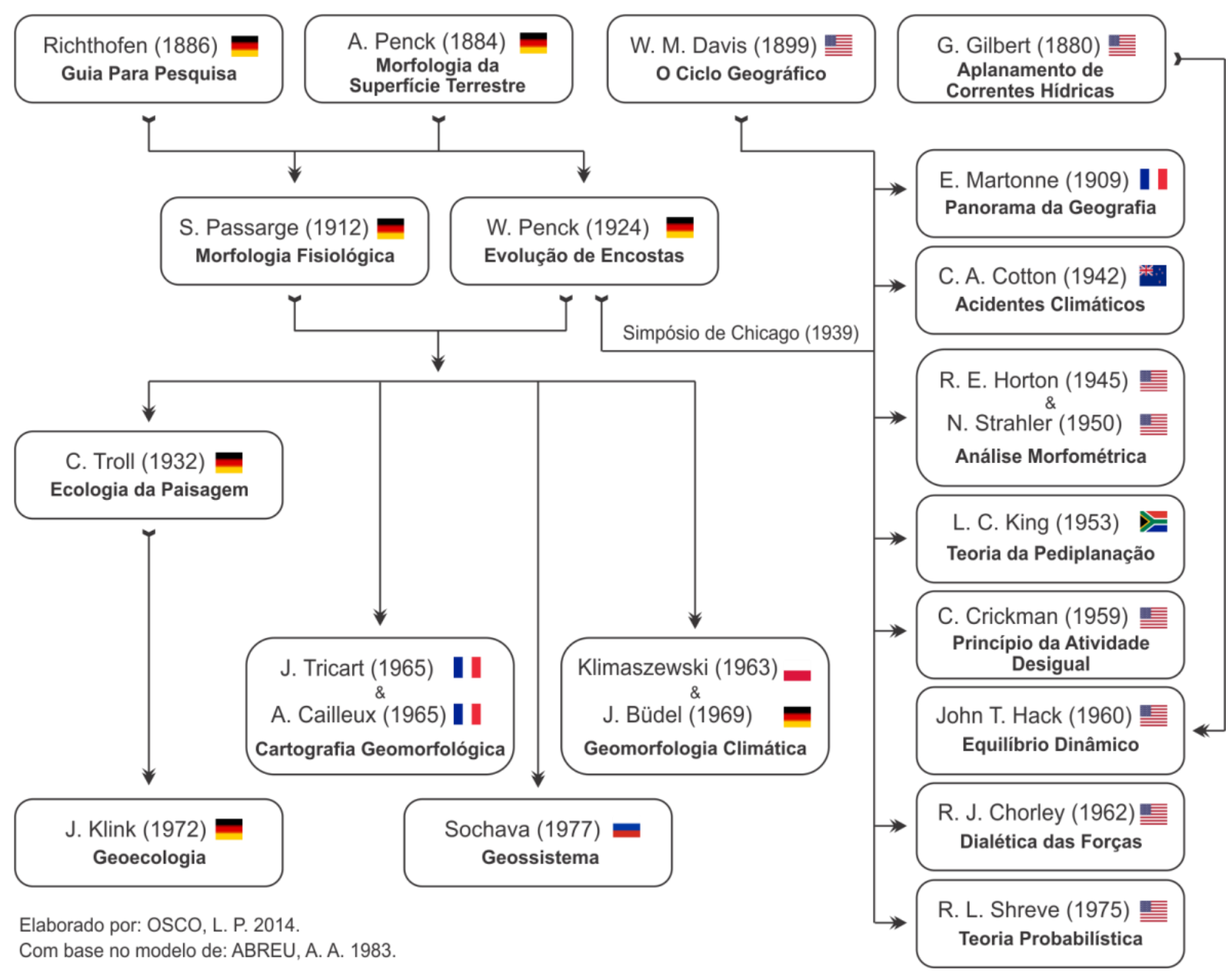

Figura 1. Principais Obras da Filogênese Teórica Geomorfológica (1880 - 1980).

Deste modo, o presente trabalho procura elucidar as diversas obras publicadas e influenciadas pela geomorfologia. Para tanto, é substancial acrescer que ambas as escolas (germânica e anglo-americana) foram responsáveis pela edificação do postulado geomorfológico, pois estas conduziram durante os últimos séculos - uma vasta parte dos estudos relacionados às características transformacionais do modelado da Terra. A verticalização dessa ciência permitiu 0 engendramento de diversas outras áreas do conhecimento geofísico, como a exemplo sua contribuição ante a análise funcional da paisagem. Deste modo, torna-se possível determinar setores de maior fragilidade ou potencialização do espaço físico, o que permite a obtenção de um sistema de organização maior, do qual contribui para as práticas de planejamento ambiental, conforme será abordado ao final deste trabalho.

\section{METODOLOGIA}

Em um primeiro momento, o aparato reflexivo construído neste artigo fundamentou-se em autores consagrados da linha de pesquisa geomorfológica, tais como Tricart (1972), Abreu (1983), Penteado (1983), Chorley et al. (1984), Ross (1992), 
Casseti (2001), Vitte (2008), dentre outros. A partir de então, construiu-se uma filogênese científica a respeito das teorias inseridas no contexto geomorfológico e paisagístico. Diante disto, salientou-se a importância desses estudos na compreensão da paisagem e do meio natural. Ulteriormente, o trabalho enfocou-se no papel da ciência abordada no desenvolvimento de práticas e análises do meio físico integrado, auxiliando na determinação de elementos primordiais para o planejamento ambiental.

\section{RESULTADOS E DISCUSSÃO}

Considera-se o viajante, geógrafo e cientista germânico Ferdinand von Richthofen, o primeiro estudioso a formalizar - advento da linha epistemológica da geomorfologia à escola germânica, por meio de sua obra "Guia Para Pesquisa" (1886). Entretanto, não apenas de Richthofen deriva a linhagem do pensamento geomorfológico alemão, pois, poucos anos depois, a obra de Albrecht Penck, intitulada "Morfologia da Superfície Terrestre" (1894), seria publicada. Apresentam-se, portanto, Richthofen e A. Penck como os "pais" da geomorfologia germânica. As posturas naturalistas de seus estudos direcionaram os pensamentos da escola às observações e análises dos fenômenos terrestres.

A geomorfologia anglo-americana, por sua vez, teve inicio próximo, destacando o estudo do geólogo e professor de literatura Grove Karl Gilbert, que por meio de sua obra "Geologia das Montanhas Henry" (1880), analisou os processos de erosão subaérea e as inúmeras alterações dos vales provocadas por rios. Christofoletti (1974), no entanto, enfatiza que os conceitos geomorfológicos neste período encontravam-se de maneira dispersa. Foi então com o geógrafo americano, William Morris Davis, por meio da obra "O Ciclo Geográfico" (1899), que viriam maiores contribuições na consolidação da ciência. A teoria do ciclo de erosão (denominada de Teoria Davisiana) resume-se a:

[...] uma superfície plana deformada bruscamente por uma ação tectônica e, sobre o relevo então formado, age a erosão que o reduz, lenta e progressivamente, através das fases de juventude, maturidade e senilidade, até nova superfície plana, a peneplanície, ponto de partia para novo ciclo. (CHRISTOFOLETTI, 1974, p. 13).

A influência de Davis sobre a geomorfologia proporcionou sua estruturação como disciplina independente e possuidora de corpo de doutrina coerente e original. A pesquisa deu coesão e vitalidade aos conceitos geomorfológicos, integrando, sistematizando e definindo a sequência normal de acontecimentos nas formas do 
relevo terrestre. Portanto, há um consenso de que enquanto a escola norte-americana fundamentava-se na Teoria Davisiana, desenvolvendo estudos de caráter quantitativos, a escola germânica distanciava-se desta visão, baseando-se nas obras naturalistas de Richthofen e A. Penck.

Entre estudos germânicos posteriores, destacam-se as obras dos pesquisadores Otto Karl Siegfried Passarge e Walther Penck. S. Passarge que, através de sua obra "Evolução de Encostas" (1924) publicada postumamente por seu pai, A. Penck, apresentou críticas à obra de Davis, fundamentando-se na ausência de conexão com a ciência geográfica do método Davisiano (principal preocupação da escola germânica). Conforme Vervloet (2012) ressalta, o trabalho de $\mathrm{W}$. Penck firmou-se na importância dos níveis de bases geral e local de erosão, condicionados pelos processos fluviais de expansão longitudinal dos canais como fator comandante na evolução de encostas. Dessa forma, evidencia-se que os estudos de W. Penck compreendiam do antagonismo entre as forças endógenas e exógenas dos processos naturais na formação do modelado.

Entretanto, a ruptura epistemológica da geomorfologia anglo-americana ocorreria somente após o Simpósio de Chicago (1939) e a Segunda Guerra Mundial (1939-1945). Segundo Casseti (2001), foi durante o
Simpósio de Chicago que as críticas do austríaco W. Penck à Teoria Davisiana conceberam novas perspectivas aos norteamericanos. Robert Elmer Horton e Arthur Newell Strahler desenvolveram estudos na área da "Análise Morfométrica" (1945 e 1950) com teorias em bacias de drenagem. Charles Calvin "Chuck" Crickmay ao aprofundar-se na evolução do relevo e em seus processos de superfície de diferentes intensidades, apresentou a "Teoria do Princípio da Atividade Desigual" (1959). Richard John Chorley, partindo da análise cronológica, introduziu o conceito da "Dialética das Forças" (1962) e Ronald L. Shreve, por sua vez, destacou-se com a obra “Teoria Probabilística” (1975).

Não obstante, conforme Oldroyd \& Grapes (2008) demonstram, os trabalhos de Lester Charles King, inseridos na corrente anglo-americana, incorporaram o modelo de W. Penck aos estudos de Davis, aprimorando a Teoria Davisiana. King enfatizava a importância dos processos superficiais e, em particular, a relação entre períodos geológicos ao soerguimento intermitente. As obras de King resultaram na "Teoria da Pediplanação" (1953), descrevendo os processos de formação de superfícies aplainadas. John Tilton Hack, por sua vez, retoma Gilbert, elaborando a "Teoria do Equilíbrio Dinâmico" (1960) ao considerar o relevo como um sistema aberto e de 
constante troca de energia e matéria com outros sistemas terrestres, vinculando-se a resistência litológica.

Assim, conforme a escola angloamericana dava continuidade ao modelo Davisiano, procurando aperfeiçoá-lo, a escola germânica manteria o seu caráter naturalista. Como resultado desta linhagem, pesquisas de caráter climatológico, cartográfico e paisagístico desenvolver-se-iam por toda a Europa. Bocco (2010) ressalta a importância da obra do geógrafo alemão Carl Troll, "Ecologia da Paisagem" (1932), onde Troll descreve contextos, antecedentes, alcances e a ideia de paisagem associando-a com os fenômenos ecológicos. Troll considerava a ecologia da paisagem como disciplina única, resultante da junção da geografia física com a ecologia, incorporando os mecanismos da geomorfologia, fitogeografia, climatologia, glaciologia e ecologia, além do levantamento espacial com intensa aplicação de técnicas aerofotográficas.

Destacam-se, ainda, os trabalhados de Jean Tricart \& André de Cayeux (1969) na área da "Cartografia Geomorfológica", os de Mieczyslaw Marian Klimaszewski e Julius Büdel. (1963 e 1969) em "Geomorfologia Climática", as obras de Hans-Jürgen Klink (apoiando-se em Troll) no campo da "Geoecologia" (1972), e os estudos de Viktor Borisovich Sochava, produzindo novos entendimentos na conceituação de
"Geossistema" (1977). Em suma, nota-se que os estudos norte-americanos e europeus permitiram o desenvolvimento da ciência geomorfológica em diversos países, principalmente no Brasil que durante décadas recentes, por forte influência da linhagem naturalística europeia, buscou compreender os processos morfoestruturais do relevo brasileiro e suas diversas interações com a paisagem ecológica.

\section{O Estudo Geomorfológico no Brasil e no}

\section{Estado de São Paulo.}

Salienta-se, conforme Vitte (2008), a influência de Emanuel de Martonne (18731955) no estudo geomorfológico brasileiro ao publicar, durante a década de 1940, dois artigos que relatavam os problemas morfológicos do Brasil. Suas obras encontram-se entre as principais contribuições para o desenvolvimento da ciência no país, pois abordaram as características das principais superfícies de erosão que esculturavam o Estado de São Paulo, destacando-se por seu caráter analítico, baseado no modelo Davisiano. Fora, entretanto, ao final da década de 1940, que o geógrafo brasileiro, Victor Ribeiro Leuzinger, ao publicar o livro "Controvérsias Geomorfológicas" (1948), descreveria o confronto entre as teorias geomorfológicas de Davis e W. Penck, avaliando qual, entre ambas, se apresentaria de forma mais 
adequada ao estudo geomorfológico brasileiro.

Leuzinger concluiu que a teoria davisiana traria graves problemas quando aplicada nas características do relevo brasileiro, pois a obra de Davis defendia que a formação do modelado dar-se-ia a partir das características do canal fluvial, o que de fato escondia sua verdadeira gênese, oriunda das relações interativas entre a geologia e os aspectos climáticos. Portanto, o início da década de 1950 seria marcado pela ruptura epistemológica da geomorfologia brasileira. O período seguiria pelo debate teórico entre os trabalhos do geógrafo brasileiro, Ruy Osório de Freitas e sua obra mais notável, "Relevos Policíclicos na Tectônica do Escudo Brasileiro" de 1951, com os trabalhos do geólogo Fernando Flávio Marques de Almeida, que, fortemente influenciado por proposições de Lester King e Jean Tricart, contestava a interpretação defendida por Freitas.

A partir de então, o professor e geógrafo brasileiro, Aziz Nacib Ab'Sáber, sob a perspectiva destes e de outros autores consagrados, estabeleceu no inicio da década de 1960 a proposta de entendimento ao relevo brasileiro sob Domínios Morfoclimáticos, tendo sua interpretação fundamentada na influência de zonalidades climáticas. Consecutivamente, outros estudos de destaque para a pesquisa geomorfológica brasileira, embora de cunho mais específico, viriam de Almeida ao publicar obras sobre a geomorfologia do Estado de São Paulo. Almeida dividiu o estado em províncias geomorfológicas, relacionando estudos geológicos na região paulista às diferentes formações do modelado. Conseguintemente, Tricart (1972) relatou a dificuldade taxonômica de subdivisão das paisagens ao criticar o mapeamento geomorfológico com base nos sistemas do relevo, pois estas divisões poderiam levar a definição de grupos com formas arbitrárias.

Neste sentido, e consoante a Casseti (2001), o geógrafo Jurandyr Luciano Sanches no ano de 1992, após os trabalhos de Tricart e sua crítica à ordem taxonômica, tendo em vista a compreensão da compartimentação do relevo, propôs seis unidades taxonômicas têmporo-espaciais distintas. Os trabalhos de Ross contribuíram para uma análise minuciosa das diferentes feições do relevo terrestre, demonstrando a relação de escalas de trabalho com o detalhamento da paisagem. Percebe-se, portanto, que a pesquisa cartográfica foi de suma importância para os trabalhos brasileiros na análise do relevo, seja por autores nacionais ou por renomados pesquisadores estrangeiros. No entanto, o estudo no país não se encontra totalmente aprofundado, e embora a ciência esteja divida em diversas 
linhas de pesquisas, a mesma se apresenta de forma branda e generalizada, o que não a classifica como uma escola geomorfológica.

\section{O Papel da Geomorfologia no Planejamento} Ambiental.

Em estudos de caráter ambiental, torna-se importante considerar os elementos geomorfológicos à abordagem integrada do meio, permitindo identificar as unidades geomorfológicas (tipos e formas do relevo, padrões de drenagem, dados altimétricos, declividade do terreno, processos erosivos e acumulativos) e associá-las às potencialidades e fragilidades da área estudada (BERGAMO \& ALMEIDA, 2006). Neste sentido, a pesquisa geomorfológica possui aplicabilidade em diferentes atividades, sejam estas antrópicas ou naturais, onde o nível de verticalização da abordagem relaciona-se à dimensão da área, objetivo do estudo, características do ambiente local e o tipo de prática a ser desenvolvida, favorecendo o planejamento ambiental, a organização e a gestão do espaço territorial.

Ademais, atualmente existem softwares de Sistemas de Informações Geográficas - SIG e Geoprocessamento que auxiliam os trabalhos geomorfológicos, aos quais são capazes de gerar diagnósticos confiáveis e informações precisas sobre o terreno, além de favorecer o aperfeiçoamento de pesquisas voltadas à paisagem (LEMES, 2009). De acordo com Centero (2003), a utilização das imagens aeroespaciais auxilia na análise visual das cenas ou dos elementos responsáveis pela formação da paisagem e morfologia do terreno. Neste sentido, ao integrar a análise ambiental à geomorfologia, Ross (2001) destaca que esta relação fornece subsídios para a adaptação de metodologias específicas ao objeto de estudo, contribuindo positivamente para a elaboração de zoneamentos, diagnósticos e unidades ambientais, podendo ser representados sinteticamente através de mapas, gráficos e tabelas.

\section{CONCLUSÃO}

Neste sentido, as unidades de paisagem acabam por serem utilizadas em estudos voltados para o planejamento ambiental, através da compreensão do comportamento dos elementos naturais e as influências das atividades antrópicas de uso e ocupação do solo em determinado tempo e espaço. Além disso, modificações oriundas do uso e ocupação do solo, e das demais atividades em superfície, criam novos arranjos e feições da paisagem, alterando o dinamismo da mesma (GUERRA \& MARÇAL, 2012). Em suma, o caráter interdisciplinar da geomorfologia, the confere a capacidade de atuar no ramo das ciências ambientais sob dois aspectos. O primeiro trata-se do planejamento ambiental, visando manter o 
equilíbrio do meio ambiente e a exploração racional dos recursos naturais, enquanto que o segundo relaciona-se à mitigação dos reflexos negativos no meio físico provocado pelas atividades antrópicas, sejam estas modificadoras da paisagem ou ocasionadoras de sua degradação (PENTEADO, 1983).

\section{REFERÊNCIAS}

ABREU, A. A. de. A teoria geomorfológica e sua edificação: análise crítica. Instituto de Geografia da USP - São Paulo, SP, Brasil. Rev. IG, São Paulo, v.4, n.112, p.5-23, 1983.

BERGAMO, E. P.; ALMEIDA, J. A. P. A importância da geomorfologia para o planejamento ambiental: um estudo do município de Fartura/SP. In: SIMPÓSIO NACIONAL DE GEOMORFOLOGIA, 6., 2006. Goiania. Anais... Goiânia,GO, 2006.

BOCCO, G. Carl Troll y la ecología del paisaje. Investigación ambiental, 2010.

CASSETI, V. Elementos de geomorfologia. Goiania: Ed. da UFG, 2001.

CENTERO, J. A. S. Sensoriamento remoto e processamento de imagens digitais.

Departamento de Geomática, Curitiba: UFPR, 2003..

CHRISTOFOLETTI, A. Geomorfologia. São

Paulo: Ed. Edgard Blücher,-1974.

CHORLEY, R. J.; DUNN, A. J.; BECKINSALE, R. P. A History of the Study of Landforms or the Development of Geomorphology. Vol 1, London ,1964.

GUERRA, A. J. T.; MARÇAL, M. S. Geomorfologia Ambiental. 4. ed. Rio de Janeiro: [s.n.], 2012.
LEMES, D. P. Relação entre a compartimentação geomorfológica e a ocorrência de ágata e ametista no município de Quaraí, RS. 2009. Dissertação (Mestrado) - Universidade Federal de Santa Maria, Departamento de Geografia., Santa Maria, RS.

HUGGETT, R.J. Geoecology: An Evolutionary Approach. London: Routledge, 1995.

OLDROYD, D. R.; GRAPES, R. H. Contributions to the history of geomorphology and Quaternary geology: an introduction. Geological Society of London, v. 301, 2008.

PENTEADO, M. M. Fundamentos de

Geomorfologia. 3. ed. Rio de Janeiro: IBGE, 1983.

ROSS, J. L. S. Geomorfologia Ambiental. 2. ed. São Paulo: Bertrand Brasil, , 2001.

ROSS, J. S. Registro cartográfico dos fatos geomorfológicos e a questão da taxonomia do relevo. Rev. Geografia, São Paulo, 1992.

TRICART, J. Carte géomorphologique ei description du milieu natural. In:

Cartofraphie géomorphologique, Paris, Centre National de la Recherch Scientifique. 1972.

VERVLOERT, R. J. H. M. Dinâmica da cobertura pedológica, rupturas geométricas e hidrogeomorfologia em uma vertente de rocha granodiorítica. Rev. Geonorte, v.2, n. 4, p.343-355, 2012.

VITTE, A. C. A construção da geomorfologia brasileira: as transformações paradigmáticas e o estudo do relevo. Geo.: Ensino \& Pesquisa, Sta Maria, v. 1 2, 2008.

Recebido para publicação em 11/08/2014 Revisado em 15/09/2014

Aceito em 16/09/2014 